\title{
El uso de Fotovoz para comparar actividades recreativas en cuatro comunidades costarricenses en vulnerabilidad social
}

Using Photovoice to compare recreational activities in four socially vulnerable Costa Rican communities

\section{Volumen 20, Número 3 \\ Setiembre - Diciembre \\ pp. 1-36}

Susana Juniu

Carmen Grace Salazar Salas

\section{Citar este documento según modelo APA}

Juniu, Susana y Salazar Salas, Carmen Grace. (2020). El uso de Fotovoz para comparar actividades recreativas en cuatro comunidades costarricenses en vulnerabilidad social. Revista Actualidades Investigativas en Educación, 20(3), 1-36. Doi. 10.15517/aie.v20i3.43618 


\title{
El uso de Fotovoz para comparar actividades recreativas en cuatro comunidades costarricenses en vulnerabilidad social
}

Using Photovoice to compare recreational activities in four socially vulnerable Costa Rican communities

\author{
Susana Juniu ${ }^{1}$ \\ Carmen Grace Salazar Salas ${ }^{2}$
}

\begin{abstract}
Resumen: Entre los años 2017 y 2019 se realizó un proyecto de investigación cualitativa con cuatro estudios independientes, uno por comunidad en vulnerabilidad social, de la provincia de San José, Costa Rica: Los Cuadros de Purral de Goicoechea, Dos Cercas de Damas de Desamparados, Tirrases de Curridabat y Alajuelita (San Felipe, Concepción y Alajuelita Centro). El propósito del proyecto fue analizar, mediante la metodología de Fotovoz, las actividades recreativas que realizaban grupos de mujeres y sus comunidades, así como los factores contextuales que facilitaban o dificultaban su participación recreativa. Este artículo tiene como objetivo compartir la comparación de los resultados de los cuatro estudios. En total, 23 mujeres tomaron fotografías durante dos semanas y seleccionaron las 16 imágenes que mejor representaban sus experiencias. Cada grupo comunitario analizó y categorizó sus fotos. Para este artículo, los temas que habían surgido en las cuatro localidades fueron analizados por las investigadoras con el método de comparación constante y el análisis de contenido. Como resultado, se obtuvieron cuatro temas nuevos generales que correspondían a factores que promovían la recreación, cinco barreras que la dificultaban y nueve tipos de actividades recreativas disfrutadas en las comunidades. No todos los temas nuevos se evidenciaron en las cuatro localidades. Los resultados mostraron que en las cuatro comunidades la falta de higiene, la inseguridad y la falta de instalaciones o de su mantenimiento afectaban la participación en la recreación. También se halló que las comunidades recibieron apoyo de entidades locales o nacionales que favorecieron las actividades recreativas. Se concluyó que las personas de estas comunidades participaban en diversos tipos de actividades recreativas y que, en condiciones difíciles, negociaron para hacerlo, a pesar de que las barreras eran más numerosas que los factores que promovían la recreación.
\end{abstract}

Palabras clave: mujer y desarrollo, actividad de tiempo libre, beneficios de recreación, diseño urbano

\begin{abstract}
Between the years 2017 and 2019, four qualitative research studies were conducted in four socially vulnerable communities in the province of San José, Costa Rica: Los Cuadros de Purral de Goicoechea, Dos Cercas de Damas de Desamparados, Tirrases de Curridabat, and Alajuelita (San Felipe, Concepción and Alajuelita Centro). The purpose of the project was to analyze, using the Photovoice methodology, the recreational activities carried out by groups of women and their communities, as well as the contextual factors that facilitated or hindered their recreational participation. This article highlights the comparison of the study results among the four communities. A total of 23 women participated in the study and took photographs for two weeks and selected the 16 images that best represented their experiences. Each community group analyzed and categorized their photos. The themes that had emerged in the four communities were analyzed by the researchers using the constant comparison method and content analysis. The results showed new themes including four factors that promoted recreation, five barriers that made it difficult, and nine types of recreational activities enjoyed in the communities. Not all the new themes were evident in the four locations. In all four communities, lack of hygiene, insecurity, and lack of facilities and poor maintenance affected participation in recreation. It was also found that the communities received support from local or national entities that favored recreational activities. It was concluded that the people of these communities participated in diverse types of recreational activities and that, in difficult conditions, they negotiated to do so, despite the fact that the barriers were more numerous than the factors that promoted recreation.
\end{abstract}

Key words: women and development, leisure time activities, recreation benefits, urban design

1 Profesora e Investigadora de la Universidad Estatal de Montclair; Nueva Jersey, Estados Unidos. Dirección electrónica: junius@montclair.edu Orcid: https://orcid.org/0000-0003$\underline{1702-7309}$

2 Profesora e Investigadora de la Universidad de Costa Rica; San José, Costa Rica. Dirección electrónica: carmengrace.salazar@ucr.ac.cr Orcid: https://orcid.org/0000-0001$\underline{6083-761 X}$

Artículo recibido: 28 de agosto, 2019 


\section{Introducción}

En las últimas décadas, la salud ha adquirido gran relevancia en el mundo a causa de las afecciones que la humanidad ha venido enfrentando. La salud no consiste en no padecer enfermedades o infecciones, sino en el bienestar integral (mental y físico) que tengan las personas (Organización Mundial de la Salud [OMS], 2011). Usualmente, al pensar en salud, la gente la asocia solo con el componente físico y relega el componente mental a segundo plano. Es por esta razón que la OMS (2013) ha fomentado un plan de acción, cuya base ha sido la frase mundial: "no hay salud sin salud mental" (p. 3).

Con la finalidad de contar con salud integral, las personas deben tener buenos hábitos. Uno de ellos es el de incorporar la recreación, de forma sistemática, en la vida. La recreación involucra aquellas actividades que se disfrutan en el tiempo libre de manera voluntaria y que promueven el desarrollo integral de las personas. Tales actividades son inclusivas pueden ser auto dirigidas, facilitadas por otra persona o por una institución u organización pública, privada o no gubernamental; realizarse individualmente, en parejas o grupos pequeños o grandes; efectuarse en cualquier momento de la vida, a lo largo de ella, en varias ocasiones o una sola vez. Además, las actividades recreativas son parte de la educación no formal (Salazar Salas, 2017), la cual se basa en el logro de objetivos, es planeada; pero no conlleva a la consecución de un título académico (Universidad Internacional de Valencia, 2015).

La relevancia de la recreación radica en los beneficios que brinda a las personas de manera individual (emocionales, sociales, intelectuales, físicos y espirituales), así como a la sociedad (familia, grupos sociales, economía, ambiente y cultura). La recreación fomenta la salud integral. Los beneficios recreativos que se pueden obtener dependen de las actividades en las que se participe: (a) recreación artística, (b) recreación al aire libre, (c) recreación intelectual, (d) recreación educativa, (f) recreación espiritual, (g) recreación física, (h) recreación social, (i) recreación turística, (j) pasatiempos y (k) servicio de voluntariado (Salazar Salas, 2017).

A pesar de los beneficios que estas actividades brindan a quienes participan en ellas, existen ciertas situaciones que las favorecen $u$ obstaculizan. Para identificar tales condiciones, en las localidades de Los Cuadros de Purral de Goicoechea, Dos Cercas de Damas de Desamparados, Tirrases de Curridabat y Alajuelita (San Felipe, Concepción y Alajuelita Centro) de la provincia de San José, Costa Rica, se realizó, en cada comunidad, un estudio independiente con mujeres y con la técnica de Fotovoz. Las participantes hallaron temas relacionados con situaciones positivas y negativas. El presente artículo tiene como 
objetivo comparar los temas identificados en las cuatro comunidades, para determinar las actividades recreativas que se realizaban en ellas y los factores que aquejaban o promovían de manera común esa participación recreativa.

\section{Fundamentación teórica}

En recreación, los factores que dificultan que las personas participen en una actividad recreativa son llamados barreras. Crawford y Godbey (1987) propusieron un modelo de tres tipos de barreras. Cuando una persona tiene particularidades o estados psicológicos que le obstaculizan recrearse se indica que tiene barreras intrapersonales. Si las relaciones con otras personas afectan la participación en actividades recreativas de un individuo, se señala que este último tiene barreras interpersonales. Otros tipos de factores que imposibilitan recrearse se denominan barreras estructurales. Algunos ejemplos de ellas incluyen la carencia de dinero, de tiempo libre, de instalaciones, entre otros. A pesar de estas situaciones, cuando una persona, realmente, desea participar en una actividad recreativa y logra efectuarla al solventar las barreras que se lo impiden, se dice que la persona efectuó una negociación (Jackson, Crawford y Godbey, 1993).

Aparte de las barreras para recrearse, las personas también enfrentan momentos difíciles. Unas suelen superarlos más fácilmente que otras. Quienes han estudiado estos comportamientos indican que existen factores protectores que ayudan a superar las situaciones adversas. Ellos son elementos o procesos que reducen o amortiguan el efecto de condiciones negativas. Se han determinado tres tipos de factores protectores: (1) los personales, (2) los familiares y (3) los socioculturales (Fínez Silva y García Montero, 2012; Jadue J., Galindo M. y Navarro N., 2005). La recreación ha sido identificada como un medio para fomentar tales procesos. Según Romero Barquero (2015), "si la recreación promueve los factores de protección se amplía entonces la posibilidad para que la resiliencia de las personas participantes mejore" (p. 73), ya que esta última es una característica individual dinámica que le permite a la persona enfrentar infortunios de un modo positivo y enriquecedor, sobreponerse a ellos y volverse emocionalmente más fuerte.

La participación en la recreación se ve afectada directa o indirectamente en las comunidades por una diversidad de barreras estructurales. A continuación, se repasan algunas. Una de esas barreras es la acumulación de basura y escombros, esta acción esto genera malos olores que afectan la salud debido a la aglomeración de desechos. Asimismo, promueve la reproducción de insectos, cucarachas y roedores que, a su vez, pueden 
ocasionar enfermedades por ser portadores de gérmenes. Además, el amontonamiento de basura y escombros bloquea alcantarillas y desagües, y esta situación provoca inundaciones que causan daños a casas y negocios (Bioenciclopedia.com, s.f.; Organización Panamericana de la Salud, 2010; Salazar Salas y Juniu, 2019a).

Otra situación que afecta a las personas es la falta de tratamiento de las aguas negras y las jabonosas, así como el desperdicio de agua potable. La omisión de tratar las aguas negras como corresponde acarrea gran daño al ambiente porque suelen ser descargadas a suelo abierto, en el subsuelo mediante tanques sépticos, en ríos, lagos y en el mar. Estas aguas contaminan el ambiente, afectan la flora y la fauna de diversos hábitats y provocan enfermedades (Rodríguez Pimentel, 2017). Esta circunstancia se complica por la falta de cordones de caño. La ausencia de estos conductos ocasiona el estancamiento de aguas, las cuales, con el tiempo, producen malos olores, mal aspecto y la proliferación de insectos que pueden generar enfermedades (Marín, 2019).

Además de esos casos, en los vecindarios también se presenta el despilfarro de agua potable. La principal causa de ese desperdicio es la infraestructura deficiente (Sostenibilidad para todos, 2018). En Costa Rica, el agua no se aprovecha al máximo porque las tuberías son viejas y con fugas subterráneas inidentificables. Existen tomas ilegales y los medidores son anticuados o han sido alterados. Además, la reparación de averías por parte de las autoridades encargadas es lenta (Lara, 2016).

La reincidencia de las situaciones mencionadas podría ser consecuencia de antivalores. Estos son conductas peligrosas, dañinas y negativas para la armonía de la sociedad (Conceptodefinición.de, 2019). Uno de los antivalores es el irrespeto, el cual consiste en una actitud negativa en contra de personas, instituciones o las normas de convivencia de la sociedad (Enciclopedia de Ejemplos, 2019).

Otra barrera que está perjudicando la salud de la población es la inactividad física. Por tal razón, la OMS (2010) ha brindado varias sugerencias para que las autoridades de cada país promuevan y mantengan los niveles recomendados de actividad física de la ciudadanía. Esta organización internacional exhorta a la construcción de infraestructura local para que las personas se ejerciten, así como de escuelas con espacios e instalaciones seguras para promover la actividad física de la población menor de edad, ya que la cantidad de personas en el mundo que participan en actividades de recreación física es baja.

El diseño del entorno físico urbano tiene gran influencia en el acceso y en las oportunidades para realizar actividad física recreativa. Recientemente, se ha hecho hincapié 
en cómo la construcción de las urbes permite que las personas se ejerciten diariamente (Koohsari et al., 2015). En Costa Rica, las principales áreas recreativas que el Gobierno ha desarrollado en San José son el Parque Metropolitano La Sabana y el Parque de la Paz, las cuales incluyen vastas áreas verdes, senderos, árboles, lagos e infraestructura para deportes competitivos o recreativos, como piscinas, gimnasios, estadios, velódromos para ciclismo y pistas de patinaje (Quirós Rossi y Asociados, 2014).

La construcción de espacios públicos, entre ellos, las áreas recreativas, debe ser planificada, esto con el objetivo de promover salud integral. En diversos barrios de Costa Rica, sobre todo donde residen personas con pocos recursos económicos, la planificación urbana no se contempla y menos con zonas recreativas. Uno de los factores que se considera relevante para fomentar la calidad de vida en las ciudades, en el futuro cercano, es la presencia de espacios públicos iluminados, con señales, acceso fácil, árboles y mobiliario acordes con el lugar (Torres Samamé, 2015), pues esas áreas promueven el contacto y el intercambio de las personas, al mismo tiempo, permiten que se favorezcan las zonas verdes.

Otras barreras que están afectando a la sociedad son la delincuencia y la falta de seguridad. El incremento de la delincuencia se vincula con falta de empleo, deserción estudiantil, vivir en zonas marginadas, falta de acción del Gobierno (Inseguridad en Costa Rica, 2012), mayor tenencia de armas de fuego, trasiego internacional de drogas y consumo nacional de drogas, entre otras razones (Kjelstad, 2018). "El principal germen de la delincuencia es la desigualdad social, la pobreza y la falta de oportunidades para estudiar y trabajar", señaló el Periódico El Gaucho (2015, párr. 7).

Lastimosamente, Costa Rica es un puente para el narcotráfico. Hay personas que se han involucrado en este negocio para ganar dinero fácilmente ante la crisis económica. En el país, algunas personas jóvenes que no concluyeron la secundaria están involucradas en el crimen organizado y son víctimas de homicidio (Loría Ramírez, 2015).

Aunado a estas barreras, la ciudadanía se queja de que el dinero del gobierno central y de sus instituciones no se usa eficientemente, pues en unas entidades falta y en otras no se usa como se presupuestó. Ante esta mala administración de los recursos económicos, el Estado debe ser más eficiente para reducir el gasto público sin perjudicar los programas para los grupos más vulnerables (Programa Estado de la Nación, Costa Rica, 2019).

En cuanto al gobierno local, la población suele criticar a las municipalidades. Esta acción podría deberse al desconocimiento del trabajo de estas organizaciones, porque ellas 
no lo divulgan (Defensoría de los Habitantes, Universidad de Costa Rica y Centro de Investigación y de Capacitación en Administración Pública, 2018).

Con la finalidad de buscar alternativas para promover su desarrollo, las comunidades han conformado agrupaciones locales. Estos grupos se organizan para luchar por la resolución de problemas que aquejan la zona y mejorar la calidad de vida de las personas que viven en ella. El éxito del trabajo grupal no es fácil de lograr. En algunas localidades, el nivel de organización es alto mientras que en otras es casi imposible de alcanzar (Calzadilla, Price, Riveros y Mateo, 2000).

Los grupos comunales organizados no son las únicas entidades locales que apoyan obras y proyectos en su área. Desde la década de 1990, cada vez más empresas en el mundo han empezado a poner en práctica la responsabilidad social corporativa (Observatorio de Responsabilidad Social Corporativa, 2019); es decir, obligaciones asumidas por ley, misión o voluntariado (Arenas Ramírez, 2016). Por tal razón, diversas organizaciones deciden apoyar proyectos de la comunidad donde están ubicadas.

La investigación que generó los datos que se compararon en este artículo usó la técnica de Fotovoz y se basó en la teoría crítica y la teoría feminista para analizar la situación de la recreación en la localidad.

En la investigación cualitativa, el uso de técnicas visuales ha aumentado recientemente: Fotovoz es una de ellas, ya que permite que personas que usualmente no suelen ser escuchadas tengan la posibilidad de emplear fotos y narrativas de su realidad como su voz (Salazar Salas y Juniu, 2019a). Ella permite la reflexión grupal de temas de la comunidad para denunciar las situaciones que afectan a la ciudadanía y evidenciar las que la favorecen (Wang y Burris, 1994, 1997).

Fotovoz es considerada como una técnica de recolección de datos por medio de fotografías (Soriano Ayala y Cala, 2016), así como un método, pues es un proceso investigativo sistemático que incluye diversas fases que van desde la determinación del tema por investigar hasta la divulgación de los hallazgos a las autoridades correspondientes (Wang, Burris y Ping, 1996). Para Riddick y Russell (2015), el objetivo de esta técnica es obtener experiencias del mundo desde el punto de vista de un grupo. Las personas participantes llegan a ser parte del equipo investigador porque captan su mundo social, luego explican lo que vieron e interpretan los significados de las vivencias fotografiadas. Según Wang, Burris y Ping (1996), cuando las mujeres no tienen participación en el proceso de la toma de decisiones relacionadas con las mejoras de los contextos sociales de la localidad, 
Fotovoz brinda la oportunidad de transmitir sus preocupaciones y necesidades a las autoridades locales.

La teoría crítica permite a las personas cuestionar la "realidad" y desafiar las condiciones que la producen (Cohen y Crabtree, 2006). Estos razonamientos empoderan al grupo oprimido o marginado y permiten alcanzar los objetivos de justicia social de la investigación (Parry, Johnson y Steward, 2013; Riddick y Russell, 2015). Cohen y Crabtree (2006) señalan que esta teoría asume la existencia de una realidad creada por fuerzas políticas, económicas, sociales, étnicas, culturales y de género que con el tiempo se han convertido en estructuras sociales naturales o reales para la población. En la recreación, esta teoría ha denunciado desigualdades en contra de mujeres, personas con capacidades diferenciadas o de ciertas clases sociales, grupos étnicos o que luchan por conservar la naturaleza, entre otros (Parry et al., 2013; Yoder y Tortosa Martínez, 2013).

En cuanto a la teoría feminista, esta ha denunciado que las mujeres han sido relegadas a segundos lugares con respecto a los hombres en diversos ámbitos y clama por igualdad (Riddick y Russell, 2015). El dominio privilegiado de los hombres ha sido evidente en la política, la economía, las artes, los deportes de rendimiento y en distintas profesiones. Esta situación también se ha presentado en la recreación, pues, aun en el siglo XIX, varias actividades y lugares eran exclusivos para los varones. La participación recreativa de las mujeres se ha visto afectada por los roles hegemónicos tradicionales familiares que la circunscriben al hogar y limitan su tiempo libre; por los prejuicios de padres y madres de familia, del gremio educador y de la sociedad en general hacia las actitudes, acciones, comportamientos y tareas que corresponden a cada sexo (Yoder y Tortosa Martínez, 2013). En la recreación, la teoría feminista ha estudiado las desigualdades de género desde la década de 1980 en países como Estados Unidos y Canadá; en especial, las barreras que impiden que las mujeres se recreen (Henderson y Hickerson, 2007).

\section{Metodología}

\subsection{Enfoque}

El enfoque de esta investigación fue cualitativo. Para lograr el objetivo de este artículo, se utilizaron la técnica de Fotovoz, el método comparativo y el análisis de contenido para examinar las actividades recreativas realizadas en cuatro comunidades en vulnerabilidad social de la provincia de San José en Costa Rica y los factores que permitían o dificultaban la 
participación en recreación. El proceso del uso de la técnica en cada comunidad se muestra en la Figura 1.

Figura 1

Proceso del uso de la técnica de Fotovoz en cada comunidad

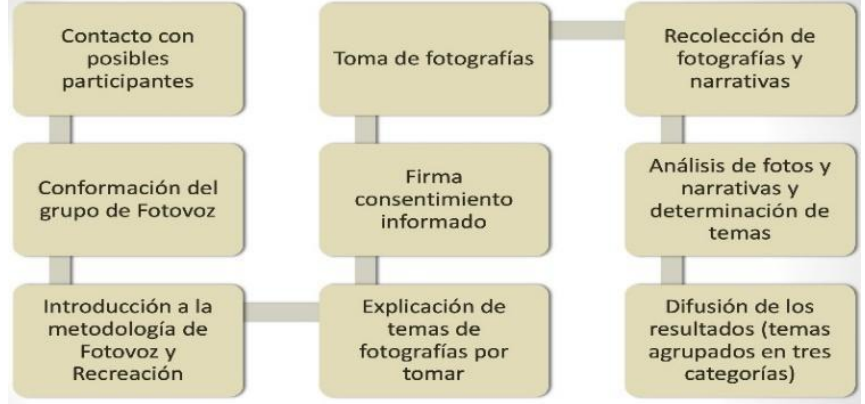

Fuente: Elaboración propia, 2019

\subsection{Unidades de estudio}

El proyecto de investigación cuyos resultados se analizan en este artículo incluyó cuatro comunidades en vulnerabilidad social de la provincia de San José, Costa Rica. Se efectuó un estudio en cada comunidad, de manera independiente, durante un semestre. Cronológicamente, la investigación se realizó en las comunidades de Los Cuadros de Purral de Goicoechea en el segundo semestre del año 2017; en Dos Cercas de Desamparados, en el primer semestre del año 2018; en Tirrases de Curridabat, en el segundo semestre del año 2018 y en Alajuelita (San Felipe, Concepción y Alajuelita Centro), en el primer semestre del año 2019 (Salazar Salas y Juniu, 2017, 2018a, 2018b, 2019b).

Según el Plan Nacional de Desarrollo 2015-2018 "Alberto Cañas Escalante", una comunidad en vulnerabilidad es considerada marginal por la escasez de recursos y la insatisfacción de necesidades básicas que tiene. Tres de las cuatro comunidades de este estudio se escogieron por la vulnerabilidad social que presentaban, pues en ese Plan estaban situadas entre los primeros diez distritos con mayor prioridad de atención durante ese periodo de años.

Esas ubicaciones fueron determinadas por la suma de las posiciones de la Línea de Pobreza (monto mínimo para cubrir bienes alimentarios y no alimentarios para subsistir), la Línea de Pobreza Extrema (monto mínimo para cubrir solo bienes alimentarios para subsistir) y las Necesidades Básicas Insatisfechas (carencia para cubrir alimentación, vestido, vivienda, educación, pago de servicios, medicamentos, transporte, entre otros) (Instituto Nacional de Estadística y Censos, Costa Rica, 2014). El distrito de San Felipe de Alajuelita ocupó la posición 6; Purral de Goicoechea, la 7 y Tirrases de Curridabat, la 8 (Ministerio de 
Planificación Nacional y Política Económica, Costa Rica, 2014). La comunidad de Dos Cercas del distrito de Damas de Desamparados se incluyó a petición del señor Alcalde de ese cantón, quién -al conocer de este proyecto- mostró interés en que esta localidad se beneficiara con la investigación. Esta localidad no se encontraba dentro de los 75 distritos prioritarios de atención del Plan Nacional de Desarrollo 2015-2018.

En la investigación participaron 23 mujeres, seis de Los Cuadros, cinco de Dos Cercas, cuatro de Tirrases y ocho de Alajuelita. Los datos recopilados de las participantes se detallan en la Tabla 1.

Tabla 1

Datos demográficos de las mujeres participantes en la investigación de cuatro comunidades costarricenses, 2019

\begin{tabular}{|c|c|c|l|l|l|}
\hline Comunidad & $\begin{array}{c}\text { Cantidad } \\
\text { Mujeres }\end{array}$ & \multicolumn{1}{|c|}{ Edad } & Estado civil & Hijos & \multicolumn{1}{|c|}{ Oficio } \\
\hline Los Cuadros & 6 & $\begin{array}{l}\text { Rango 28-48 } \\
\text { Promedio 38,83 }\end{array}$ & $\begin{array}{l}\text { Solteras (3) } \\
\text { Casadas (3) }\end{array}$ & Rango 0-4 & Amas de casa (6) \\
\hline Dos Cercas & 5 & $\begin{array}{l}\text { Rango 41-54 } \\
\text { Promedio 47,8 }\end{array}$ & $\begin{array}{l}\text { Solteras (2) } \\
\text { Casadas (2) } \\
\text { Divorciada (1) }\end{array}$ & Rango 0-2 & $\begin{array}{l}\text { Ama de casa (1) } \\
\text { Empresaria (1) } \\
\text { Vendedora (1) } \\
\text { Comerciante (1) } \\
\text { Estilista (1) }\end{array}$ \\
\hline $\begin{array}{c}\text { Tirrases } \\
\begin{array}{c}\text { Alajuelita (San } \\
\text { Felipe, } \\
\text { Concepción, } \\
\text { Alajuelita } \\
\text { Centro) }\end{array}\end{array}$ & 8 & $\begin{array}{l}\text { Rango 25-40 } \\
\text { Promedio 34 }\end{array}$ & $\begin{array}{l}\text { Unión libre (2) } \\
\text { Casadas (2) }\end{array}$ & Rango 1-3 & $\begin{array}{l}\text { Amas de casa (2) } \\
\text { Diseñadora gráfica (1) } \\
\text { Fotógrafa (1) }\end{array}$ \\
\hline
\end{tabular}

Fuente: Elaboración propia con datos proporcionados por todas las participantes

\subsection{Técnicas de recolección de la información}

La recopilación de datos tuvo dos partes. Primero se utilizó la técnica de Fotovoz para identificar las actividades recreativas realizadas en cada una de las cuatro comunidades, así como los factores contextuales que facilitaban o dificultaban la participación recreativa. Posteriormente, para este artículo, se analizaron los 34 temas identificados en las cuatro comunidades citadas, con sus fotografías y narrativas.

En cada comunidad, se realizaron cuatro reuniones. En la primera se brindó la inducción de la investigación, de la técnica de Fotovoz, de recreación y sus beneficios, y se firmó el consentimiento informado. Las mujeres seleccionaron un pseudónimo para proteger su identidad y brindaron algunos datos demográficos. En la segunda reunión, aproximadamente dos semanas después, se recolectaron las fotografías y la narrativa de 
cada una de las imágenes, la cual consistía en una explicación del mensaje de la foto. La mayoría de las fotografías fueron trasladadas de la cámara fotográfica o teléfono celular a una computadora. En las últimas dos comunidades (Tirrases y Alajuelita), también se usaron el correo electrónico y la aplicación de WhatsApp para recolectar las fotos y las narrativas.

En la tercera reunión, las mujeres de cada comunidad, en conjunto, analizaron todas las fotografías y narrativas, las agruparon en temas comunes y les dieron nombre. Las investigadoras brindaron asesoría de cómo realizar tal actividad. En la cuarta reunión, las investigadoras presentaron a las mujeres un borrador del documento con los resultados que se entregaría por escrito y se expondría de manera verbal a las autoridades locales. Las mujeres lo revisaron, corrigieron y aprobaron.

\subsection{Procesamiento de análisis}

En cada localidad se obtuvo temas que se agruparon en tres grandes categorías de fotos: (a) las actividades recreativas que se realizaban en la comunidad, (b) los factores que promovían la recreación, que se llamaron "factores" en los resultados de las investigaciones y (c) los factores que obstaculizaban la participación recreativa y que se denominaron "barreras". En los cuatro estudios independientes se identificaron un total de 34 temas: 13 barreras que dificultaron la recreación en las cuatro comunidades, 12 factores que la promovieron y nueve tipos de actividades recreativas en las que se participó entre las cuatro localidades.

Para el análisis reportado en este artículo, se utilizó el método comparativo constante y el análisis de contenido. El método comparativo constante consiste en cotejar las variables que se investigan para identificar semejanzas y diferencias, con la finalidad de describir, explicar o enriquecer los conocimientos del tema en estudio (Gómez Díaz de León y de León de la Garza, 2015). Por su parte, el análisis de contenido se basa en examinar y cuantificar las ideas de documentos, el significado de los temas, de las frases y palabras. El estilo del texto no se analiza (López Noguero, 2002).

Se realizaron tres comparaciones. Primero, la comparación de la información obtenida por las mujeres participantes en las cuatro comunidades consistió en (a) transcribir en una tabla los datos que se les había solicitado en la inducción, (b) comparar los datos, (c) calcular promedios de edad por comunidad, (d) determinar rangos de edad y de la cantidad de hijos, por comunidad y (e) contabilizar la frecuencia de mujeres participantes, su estado civil y oficio, por comunidad. 
Segundo, los pasos que se siguieron en la comparación de los temas fueron los mismos para los factores que promovieron la participación recreativa en cada comunidad y para las barreras que la dificultaron. Este procedimiento consistió en (a) transcribir los nombres de temas identificados en cada comunidad, (b) analizar los nombres de los temas y el contenido de sus fotos y narrativas, (c) comparar y reagrupar los temas según similitudes que los justificaran, (d) dar nombres a los nuevos temas que abarcaban varios temas iniciales, o mantener el nombre como se había empleado en el reporte de los hallazgos de alguna comunidad, (e) seleccionar una foto y su narrativa como ejemplo de cada tema, y (f) buscar literatura para respaldar los temas resultantes del análisis.

Tercero, la comparación de las actividades recreativas en las que se había participado en cada comunidad se basó en (a) transcribir los nombres de los grupos de actividades recreativas $(A R)$ identificadas en las cuatro localidades, (b) comparar los tipos de AR realizadas entre todas las comunidades, sus fotos y narrativas, (c) emplear los mismos nombres de los tipos de AR usados en las comunidades, (d) comparar los tipos resultantes de AR con la clasificación utilizada en la investigación (Salazar Salas, 2017), (e) seleccionar una foto y su narrativa como ejemplo de cada AR y (f) buscar literatura para respaldar cada tipo de AR resultante de la comparación. Este proceso se resume en la Figura 2.

\section{Figura 2}

\section{Proceso de la comparación entre actividades recreativas, barreras y factores identificados en} las cuatro comunidades, 2019

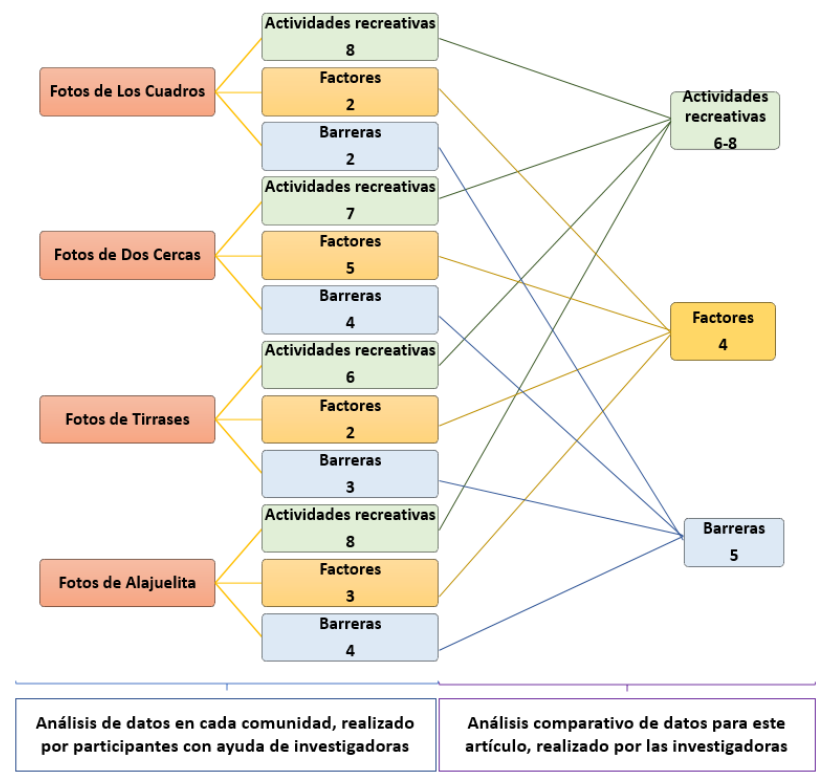

Fuente: Elaboración propia, 2019 


\section{Resultados y su análisis}

Los datos que se presentan a continuación pretenden dar respuesta al objetivo de este artículo. Ellos se basan en las fotografías brindadas por las participantes de cada comunidad, en los temas que ellas identificaron y en el análisis comparativo de todos esos temas. La información de esta sección corresponde a:

$\checkmark$ La comparación entre los datos demográficos de las participantes de las cuatro comunidades.

$\checkmark$ Los resultados de la comparación entre:

olas barreras que dificultaron la recreación en esas localidades, olos factores que la promovían, olas actividades recreativas realizadas en las comunidades,

$\checkmark$ Ejemplos del empoderamiento mostrado por las mujeres por su participación en el estudio.

Los hallazgos de este estudio cualitativo se presentan junto con manifestaciones de las personas autoras en el campo de la Recreación acerca de dichos temas.

\subsection{Barreras que dificultaron la participación en actividades recreativas}

Las barreras identificadas en las cuatro comunidades como aquellas que impedían que las mujeres participantes y otras personas de las localidades pudieran recrearse fueron trece. Ellas son:

$\checkmark$ Los Cuadros: (a) Desilusión (tristeza/ depresión) por factores negativos: basura, falta de higiene, delincuencia, desinterés de los demás habitantes por la comunidad, invasiones de terrenos públicos y (b) Manipulación de la pobreza: robo y venta de agua potable, robo y venta de electricidad, engaño a instituciones públicas para obtener ayudas.

$\checkmark$ Dos Cercas: (a) Basura en lugares públicos, (b) Falta de respeto por los demás miembros de la comunidad, (c) Falta de seguridad en parques infantiles y (d) Falta de construcción y mantenimiento de infraestructura.

$\checkmark$ Tirrases: (a) Mejoras que la Municipalidad y otras instituciones deben realizar en la comunidad, (b) Basura en toda la comunidad y (c) Falta de mantenimiento de edificios nuevos.

$\checkmark$ Alajuelita: (a) Contaminación ambiental con basura y escombros, (b) Desperdicio y no cauce de aguas, (c) Irrespeto a la ley y (d) Falta de seguridad. 
La comparación de las 13 barreras generó otras cinco nuevas que obstaculizaban recrearse en las cuatro comunidades. Algunas de ellas conservaron los nombres que las mujeres habían escogido, y, en otros casos, son el resultado de la fusión de varios temas. Una barrera se evidenció en las cuatro comunidades, dos barreras en tres localidades, una en dos comunidades y una en una localidad. En las cuatro comunidades solo se identificaron barreras estructurales. Las nuevas cinco barreras son (a) Peligros para la salud, (b) Desinterés e irrespeto por las demás personas y por las leyes, (c) Delincuencia y falta de seguridad, (d) Falta de construcción de infraestructura recreativa o de mantenimiento de la existente y (e) Manipulación de la pobreza. Algunas incluyen sub-barreras. Dos de ellas se ilustran con fotos y narrativas.

Paparazzi, una participante de la comunidad de Concepción de Alajuelita, externó con precisión la relación entre las barreras y la recreación:

yo veo que ese es un tema de todos, porque estamos coincidiendo en lo de la basura, en los carros montados en la acera y también estamos coincidiendo, igual, en que hay recreación. Pero todo eso también influye en que la recreación no es la misma si hay inseguridad, si hay basura, si hay contaminación.

\subsubsection{Barrera 1: Peligros para la salud}

Esta barrera incluye la acumulación de basura y de escombros, así como el mal o inexistente cauce de aguas negras y jabonosas y el desperdicio de agua potable.

\subsubsection{Sub-barrera: Acumulación de basura y escombros}

La acumulación de la basura produce metano y dióxido de carbono, que son gases dañinos para el ambiente y para los seres humanos. Estas emanaciones pueden provocar trastornos respiratorios, cardíacos, gastrointestinales y dermatológicos. La basura de aparatos electrodomésticos contiene metales tóxicos que contaminan el aire y las aguas. Además, los roedores y los insectos proliferan cuando la basura se descompone. La acumulación de basura provoca malestar físico y desánimo en las personas por la falta de aseo, cuido y responsabilidad de quienes habitan en la localidad (Campos, 2016; Pérez Del Pozo, 2019).

Esta sub-barrera fue reflejada por fotografías de las cuatro comunidades. Al respecto, Blanca Rosa, una participante de Los Cuadros, manifestó en la narrativa de una foto, "Los precarios no sacan la basura y la tiran en zonas de reservas. No se está cuidando el lugar 
donde vivimos, ni nos preocupamos por verlo limpio. Tenemos que trabajar para educar a las comunidades."

Solimar, una participante de Tirrases, indicó:

Este basurero es muy incómodo para todos los vecinos que estamos enfrente o a la par de este basurero porque depositan todo tipo de restos de animales y electrodomésticos. En cada ocasión, le prenden fuego y el humo es una contaminación mayor. Sería bueno que presenten una propuesta para que las personas [del barrio] de Miravalles 2 tengan su propio basurero y no bajen a contaminar y a hacer más desorden. Sería bueno fomentar más el reciclaje, dar las charlas más cerradas a cada barrio y hacer que la gente se involucre y tome conciencia de parar la contaminación ambiental.

Campos (2016) señaló que este problema es responsabilidad compartida por la ciudadanía y las autoridades a cargo. La primera, por el consumismo y el no desechar los residuos como corresponde y, la segunda, por incumplir con la apropiada recolección de basura y no castigar a quienes ensucian los lugares públicos.

\subsubsection{Sub-barrera: Desperdicio y no cauce de aguas}

En esta sub-barrera se encontraron tres situaciones, una en Los Cuadros y dos en Alajuelita. Por un lado, se halló falta de higiene en la comunidad de Los Cuadros porque las aguas negras y las jabonosas no recibían el tratamiento adecuado. Para contrarrestar esa situación es necesario mantener la higiene para prevenir enfermedades y no afectar plantas y animales (OMS, 2017; Rodríguez Pimentel, 2017; Salazar Salas y Juniu, 2019a).

Por otro lado, se detectó que, en Alajuelita, no se arreglaban rápidamente las fugas de agua potable en las calles y que tampoco existían cordones de caño que canalizaran el agua proveniente de casas y negocios. La falta de esos conductos ocasiona el estancamiento de aguas, las cuales, con el tiempo, producen malos olores, mal aspecto y la proliferación de insectos que pueden generar enfermedades (Marín, 2019).

Las razones por las que se desperdicia agua en las ciudades son diversas, pero la deficiente infraestructura es la principal causa (Sostenibilidad para todos, 2018). Esta situación podría ser el resultado de que, como señalaron Echeverría y Cantillo (2013), cuando los recursos que se tienen son muchos y gratuitos, las personas no los aprecian y 
suelen desperdiciarlos. Esa situación es la que ha ocurrido en Costa Rica con el agua y con la falta de considerar la correcta administración de este recurso como prioridad nacional.

Paparazzi reiteró el tema del desperdicio de agua en el distrito de Concepción de Alajuelita cuando señaló que había "una fuga de agua que ya le llevo contando cinco meses y no la reparan. Es un río. Está por la Guardia Rural, a la par del Bar 8 de diciembre”.

\subsubsection{Barrera 2: Desinterés e irrespeto por las demás personas y por las leyes}

En la actualidad, el irrespeto a las personas y a las leyes está aumentando en la sociedad.

El irrespeto es un antivalor que consiste en una actitud negativa en contra de personas, instituciones o las normas de convivencia de la sociedad (Enciclopedia de Ejemplos, 2019). Por su parte, los antivalores son conductas peligrosas, dañinas y negativas para la armonía de la sociedad (Conceptodefinición.de, 2019).

El irrespeto a la ley de tránsito ocasiona que algunos automóviles no puedan ser sacados de la cochera de las casas, que no se pueda "caminar por la acera sin tener que lanzarse a la calle y [aumenta] el riesgo de que el niño se queme un brazo con la mufla caliente de una moto estacionada en la acera" (Ministerio de Obras Públicas y Transportes, Costa Rica, 2018, párr. 1). Esta situación ocasiona que la Policía de Tránsito de Costa Rica efectúe cientos de sanciones anuales a personas que estacionan indebidamente.

En las comunidades de Los Cuadros, Dos Cercas y San Felipe de Alajuelita, el irrespeto y el desinterés por las demás personas que viven en ellas y por las leyes se evidenció en casos como:

$\checkmark$ Los Cuadros: (a) la invasión de parques infantiles para construir viviendas informales, para convertirlos en parqueos o en basureros a cielo abierto; (b) la falta de cuido de instalaciones por parte de la comunidad, no se bota la basura en los basureros, se rayan paredes y poyos, no se juntan excrementos de mascotas; (c) la quema de basura sin control, la cual causa humo que afecta a quienes viven cerca de ese lugar y que pone en peligro a las viviendas aledañas. En ocasiones, se ha tenido que llamar a los bomberos para que apaguen el incendio incontrolable.

$\checkmark$ Los Cuadros, Dos Cercas y Alajuelita: (a) el estacionamiento ilegal permanente o temporal de vehículos no solo en parques, sino también en zonas verdes, aceras y calles. Además, en algunos de estos carros "chatarra" que pasaban semanas en el mismo sitio, personas delincuentes solían dormir o guardar drogas y armas; (b) la 
acumulación de basura y escombros en lugares públicos, como aceras, calles, parques y lotes baldíos causaron problemas salubres y de mal aspecto de las comunidades.

$\checkmark$ Dos Cercas y Alajuelita: el uso de aceras mal construidas ponía en peligro a la ciudadanía. Muchas personas tenían que desplazarse por las calles, a pie o en sillas de ruedas por temor a caerse por los desniveles que presentaban las aceras, o tenían que caminar con mayor cuidado para no caerse en las manillas levantadas de las tapas de las aceras.

$\checkmark$ Alajuelita: el consumo de licor en parques recreativos de las comunidades.

\subsubsection{Barrera 3: Delincuencia y falta de seguridad}

Esta barrera incluye dos temas de gran preocupación para la ciudadanía del país.

\subsubsection{Sub-barrera: Delincuencia}

En la comunidad de Los Cuadros, las mujeres identificaron dos situaciones de delincuencia en dos fotos. En una se observaban dos jóvenes con armas en mano y en la otra, personas que se reunían para realizar actividades delictivas (Salazar Salas y Juniu, 2019a). La participación de la juventud en actos delictivos ha aumentado, en especial, en el narcotráfico. Las personas involucradas en este negocio han incluido a costarricenses, quienes ven en esta actividad una forma fácil de ganar dinero ante la dificultad de encontrar trabajo por la situación económica que ha enfrentado el país en las últimas décadas (Ventas, 2015).

\subsubsection{Sub-barrera: Falta de seguridad}

En Dos Cercas y en Alajuelita, la falta de seguridad que se evidenció no solo fue delictiva, sino también de otros tipos, como el mal estado de algunos aparatos de parques infantiles, venta de drogas y balaceras, lotes baldíos con maleza alta donde podían esconderse delincuentes, desplazamiento forzado de las personas por las calles, ya que en las aceras había vehículos estacionados, se carecía de aceras o las existentes estaban mal construidas o sin mantenimiento, entre otros temas.

Con respecto al caso de las aceras mal construidas, ellas son el producto de la falta de conocimiento de la ciudadanía de las especificaciones de construcción y de la calidad del material que se debe usar en la obra. También, en ocasiones, ha faltado asesoría de parte de la municipalidad correspondiente (Jiménez, 2016). 
La foto de la Figura 3 muestra un ejemplo del tema de la falta de seguridad. Antonieta, una participante de Alajuelita Centro, comentó lo siguiente en su narrativa.

Figura 3

Inseguridad por falta de aceras en Alajuelita Centro

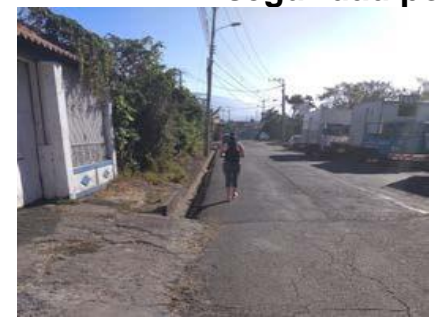

"Falta de acera en toda la cuadra que está detrás de la iglesia católica del centro, donde se va a correr y a caminar"

Fuente: Antonieta, participante en la investigación de Alajuelita (2019)

\subsubsection{Barrera 4: Falta de construcción de infraestructura recreativa o de} mantenimiento de la existente

En Los Cuadros, Dos Cercas y Tirrases se denotó la carencia de infraestructura o la falta de mantenimiento de las edificaciones existentes.

\subsubsection{Sub-barrera: Falta de construcción de infraestructura recreativa}

La infraestructura recreativa incluye diversidad de edificaciones. La más común suele ser la deportiva por la alta demanda que tiene de parte de la ciudadanía. La participación en recreación física es importante para mantener la salud. En el año 2010, cerca del $23 \%$ de la población mundial de 18 o más años no era físicamente activa y un $81 \%$ de adolescentes entre 11 y 17 años no realizaba actividad física. Este comportamiento era reforzado por el temor a la violencia y la delincuencia fuera del hogar, el tráfico, la mala calidad del aire, la contaminación y la carencia de instalaciones deportivas y recreativas, aceras y parques (OMS, 2018).

La carencia de infraestructura recreativa y la necesidad de que se construyan más instalaciones se detectó en las comunidades de Los Cuadros y de Dos Cercas. Algunas de las instalaciones que hacen falta son: parques de juegos para menores, área para patinar, área para bicicletas, entre otras. La foto de la Figura 4 muestra una de las estructuras señaladas como requeridas, por Mar, una participante de la comunidad de Dos Cercas. 
Figura 4

Falta de construcción de infraestructura para patinar en Dos Cercas

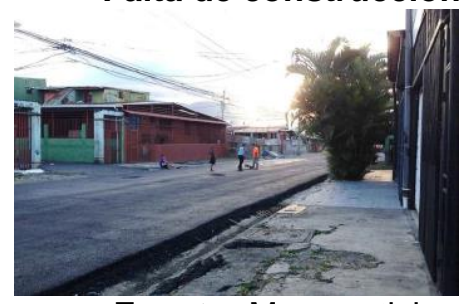

"Se debe tener un lugar donde los niños puedan patinar y no que lo hagan en la calle, donde corren riesgo sus vidas"

Fuente: Mar, participante en la investigación de Dos Cercas (2018)

A pesar de que la construcción de instalaciones deportivas y recreativas en el mundo se ha incrementado en las últimas décadas, producto de la valorización de la recreación por los beneficios que ella brinda a la salud individual y a la sociedad (Tendencias en Arquitectura Deportiva y Recreativa, 2016), esta no es la realidad en todos los rincones de Costa Rica. Las comunidades de este estudio son ejemplos de esa situación.

\subsubsection{Sub-barrera: Falta de mantenimiento de la infraestructura recreativa existente}

En el año 2015, Benavides afirmaba que en el país se debería invertir entre el 3,7\% y el 4\% del Producto Interno Bruto (PIB) en infraestructura, pero solo se estaba destinando el 0,17\%. La infraestructura a la que se refiere este autor, así como los medios de comunicación y algunos grupos interesados, es la vial, la comercial, la industrial, la turística, la portuaria y viviendas. El Estado se enfoca en ellas porque considera que pueden ayudar a mejorar la economía nacional. Aparte del sector de turismo, la infraestructura recreativa no tiene un lugar de prioridad en la lista de obras del país (AFP, 2019). En ciertas ocasiones, se da relevancia a las instalaciones deportivas, cuando se requieren para realizar competencias internacionales en las que Costa Rica es la sede.

En el país se han construido diversos parques urbanos e instalaciones deportivas. Varias de estas últimas solían ser reparadas para celebrar los Juegos Deportivos Nacionales en diversos cantones del país. La norma con estas infraestructuras era que después de las competencias, ellas quedaban en manos de organizaciones comunales que, en la mayoría de los casos, no contaban con presupuesto para brindarles el mantenimiento necesario. En el año 2016, el Consejo Nacional del Deporte y la Recreación decidió que las justas deportivas de los años 2016, 2017 y 2018 se realizaran en cantones de San José y Cartago que tuvieran instalaciones apropiadas. Esta decisión ahorraría dinero en tiempos de dificultades fiscales, permitiría una mejor competencia al contarse con infraestructura en 
buen estado y no se tendría que construir instalaciones que después podrían llegar a deteriorarse por falta de cuido (Meléndez, 2016).

La necesidad de brindar mantenimientos preventivo y correctivo se determinó en las siguientes instalaciones:

$\checkmark$ Los Cuadros: polideportivo, parques infantiles y zonas verdes

$\checkmark$ Dos Cercas: cancha multiuso, zona en la que se juega fútbol

$\checkmark$ Tirrases: polideportivo El Tirrá: techo y servicios del gimnasio, luces de cancha de fútbol.

\subsubsection{Barrera 5: Manipulación de la pobreza}

En la comunidad de Los Cuadros, las fotos reflejaron tres situaciones que las mismas señoras participantes llamaron "Manipulación de la pobreza". Ellas estaban molestas de que algunas personas se aprovecharan de otras o de su situación económica para obtener beneficios sin mayor esfuerzo, y con engaño. Los temas se relacionaban con el robo de agua y su venta ilegal, el robo de electricidad y su venta ilegal, y el engaño a instituciones públicas para obtener ayuda estatal (Salazar Salas y Juniu, 2017, 2019a).

El Informe del Programa Estado de la Nación del año 2016 hizo mención del robo de agua en barrios marginales por las dificultades que tiene el Instituto Nacional de Acueductos y Alcantarillados (AyA) para medir el consumo del líquido en esos lugares. También indicó el alto costo de la electricidad en Costa Rica, en comparación con otros países centroamericanos.

En cuanto al engaño a las instituciones estatales para obtener apoyo, este actuar podría deberse a la ayuda sin control de los gobiernos a las personas de escasos recursos cuando están en campaña política o mediante programas de bien social. Según Juan (2020), muchas personas se aprovechan de estas situaciones para victimizarse como "pobres" para recibir algún beneficio sin mucho esfuerzo. Según indicaron las participantes de Los Cuadros, algunas instituciones del gobierno no corroboran los datos que les dan diversas personas, cuya finalidad es ser clasificadas como "de pobreza extrema" para recibir ayuda del Estado (Salazar Salas y Juniu, 2019a).

\subsection{Factores que facilitaron la participación en actividades recreativas}

Los doce factores identificados por las participantes como aquellos que favorecieron la recreación en las cuatro comunidades fueron: 
Los Cuadros: (a) Apoyo gubernamental y privado, y (b) Organización comunal

$\checkmark$ Dos Cercas: (a) Satisfacción por logros y cambios en comunidad, (b) Infraestructura recreativo-deportiva, (c) Apoyo de la Asociación de Desarrollo, (d) Respuesta de la Municipalidad y (e) Propuesta para incentivar a jóvenes a mejorar los espacios comunes

$\checkmark$ Tirrases: (a) Emprendedurismo y (b) Entidades e infraestructura que benefician a la comunidad

$\checkmark$ Alajuelita: (a) Apoyo de entidades de la comunidad, (b) Aprendiendo a cuidar la comunidad por parte de jóvenes y niños, y (c) Capacitaciones en leyes a dirigentes comunales y Comité Comunitario de Emergencias.

Los cuatro temas que se obtuvieron de la comparación de los 12 factores que promovieron la participación en actividades recreativas en las cuatro comunidades son (a) Apoyo recibido del gobierno nacional y del local, y de empresas $u$ organizaciones comunales, (b) Organización comunal, (c) Infraestructura recreativa que se posee, (d) Involucramiento de la niñez y la juventud para cuidar la comunidad. Dos de los factores se ilustrarán con fotos y narrativas de las mujeres participantes. Algunos tienen subfactores.

\subsubsection{Factor 1: Apoyo recibido del gobierno nacional y del local, y de empresas u} organizaciones comunales

Este factor se identificó en las fotografías de las cuatro comunidades, pero de diferentes maneras.

\subsubsection{Subfactor: Apoyo recibido del gobierno nacional}

Las obras que el gobierno realiza en las comunidades del país son específicas. Por razones presupuestarias, el Poder Ejecutivo decide cuáles inversiones puede efectuar cada año. En el informe de labores de mayo del año 2019, el Presidente de la República, Carlos Alvarado Quesada, mencionó diversos programas, como el de "Puente al Desarrollo", que algunas instituciones han venido ofreciendo a la población y varias de las comunidades que se beneficiarán con ese tipo de ayuda gubernamental. Las localidades que conformaron esta investigación no estaban incluidas en este informe (Presidencia de la República de Costa Rica, 2019). 
A pesar de esta situación, las fotos y las narrativas entregadas por las participantes evidenciaron el apoyo del gobierno nacional recibido por las cuatro localidades, el cual fue de dos tipos. Por un lado, las comunidades de Los Cuadros y de Dos Cercas contaron con respaldo del gobierno central mediante el Ministerio del Deporte y la Recreación, el Ministerio de Educación Pública, el Ministerio de Seguridad Pública y el Ministerio de Justicia y Paz. Por otro lado, entre todas, las cuatro comunidades recibieron ayuda de, al menos, once entidades autónomas y públicas.

En la comunidad de Dos Cercas, Lucecita indicó, en relación con la construcción del parque, "un logro más en la comunidad: construir un parque gracias a la Municipalidad, al Ministerio de Justicia y Paz, y a muchas mujeres que aportaron sus talentos".

\subsubsection{Subfactor: Apoyo recibido del gobierno local}

Aunque en el país, el concepto de la ciudadanía acerca de las municipalidades no suele ser positivo, las fotografías de Los Cuadros, Dos Cercas y Tirrases evidenciaron que esas tres comunidades se beneficiaron con el apoyo del respectivo gobierno local mediante los diversos departamentos y servicios que brindan. Solimar, de Tirrases, comentó "[La Cometa de la Municipalidad es un] sitio que ha progresado y ha traído crecimiento a la comunidad, enseñando cursos recreativos y aprendizaje para la comunidad. Se está aprovechando al máximo".

Con respecto a este tema, la Municipalidad de Curridabat (2020) reporta cuatro centros de desarrollo humano en el cantón, "La Cometa" en el distrito de Tirrases, "El Tiribí" en el distrito de Sánchez, "La Casa del Pueblo" en el distrito de Granadilla Norte y "El Hogar" en Curridabat Centro. La Cometa brinda programas de apoyo para el estudio, cursos libres, cursos artísticos y educación abierta para promover el crecimiento integral de las personas de la comunidad.

\subsubsection{Subfactor: Apoyo recibido de empresas u organizaciones comunales}

En el país, cada vez es mayor la cantidad de empresas que ponen en práctica la responsabilidad social, la cual brinda diversos beneficios a la sociedad. En el año 2017, el $29 \%$ de las grandes empresas participantes en una investigación señaló que realizaba actividades de voluntariado, relacionadas con las necesidades de las localidades en las que estaban ubicadas (Club de Excelencia en Sostenibilidad de España, 2017). 
En cuanto al apoyo brindado por empresas o grupos, las fotos mostraron que las cuatro localidades lo obtuvieron, por lo menos, de una entidad.

$\checkmark$ Los Cuadros: Asociación Beraca Centro Diurno Adulto Mayor, Asembis, iglesias, empresa de buses de Purral Arriba, Universidad Santa Paula, instructora de capoeira, instructora de yoga, Red de Cuido de Goicoechea, dueño de carnicería, grupos de mujeres, Casa de la Cultura, Escuela Tinoco, Comité administrador de vecinos de una instalación deportiva, Comité Distrital de Deportes y Recreación de Purral, Asociación de Desarrollo Integral de Los Cuadros

$\checkmark$ Dos Cercas: Asociación de Desarrollo, kínder privado, grupo de vecinos, grupo de atletismo

$\checkmark$ Curridabat: La Cometa de Tirrases. Aunque esta es una entidad municipal, para las mujeres del estudio es un centro de organización y desarrollo comunal

$\checkmark$ Alajuelita: Asociación de Desarrollo García Monge de San Felipe y Recicladora.

\subsubsection{Factor 2: Organización comunal}

En las comunidades, la familiaridad de las personas favorece que ellas se unan y que se organicen para mejorar las condiciones locales de vida (Gamboa Gamboa, 2018). Esta es la tónica en muchos distritos de Costa Rica y, por tal razón, existen diversas asociaciones de desarrollo, cuyos objetivos se centran en el bienestar de la comunidad.

Este tipo de organización fue relevante en la oferta de actividades recreativas en varias comunidades de esta investigación. En tres de las cuatro comunidades, las fotos evidenciaron grupos organizados de las personas vecinas:

$\checkmark$ Asociación Beraca Centro Diurno Adulto Mayor de Los Cuadros

$\checkmark$ Asociación de Desarrollo de Dos Cercas

$\checkmark$ Asociación de Desarrollo García Monge de San Felipe de Alajuelita

En la comunidad de Tirrases, las fotos no evidenciaron la intervención de una asociación de desarrollo. No obstante, las mujeres participantes de este distrito, al igual que las de las otras tres localidades, mostraron tener empoderamiento para trabajar por su comunidad. 


\subsubsection{Factor 3: Infraestructura recreativa que se posee}

En Costa Rica, de las instalaciones recreativas existentes, las deportivas son las más numerosas, a pesar del rezago de cuatro décadas que tiene el país en este tipo de infraestructura (Murillo Arce, 2016).

Las cuatro comunidades del estudio poseían instalaciones que permitían la organización de diversos tipos de actividades recreativas.

$\checkmark$ Los Cuadros: Polideportivo, salón de la Asociación Beraca Centro Diurno Adulto Mayor, zonas verdes, gimnasio, contenedor de la Casa de la Cultura, área de patinaje, cancha de fútbol

$\checkmark$ Dos Cercas: Villa Olímpica, Parque de Dos Cercas, parques infantiles, salón comunal

$\checkmark$ Tirrases: El Tirrá, La Cometa, las máquinas para hacer ejercicio, el skate park

$\checkmark$ Alajuelita: parques comunales, parque de Alajuelita Centro, salón comunal de San Felipe, playground en el Barrio El Jardín de Concepción, playground en San Felipe, zonas verdes.

En la Figura 5 se aprecia una de estas instalaciones que explicó Magdalena, una participante de Los Cuadros.

Figura 5

Contenedor en el que se enseña Karate en Los Cuadros

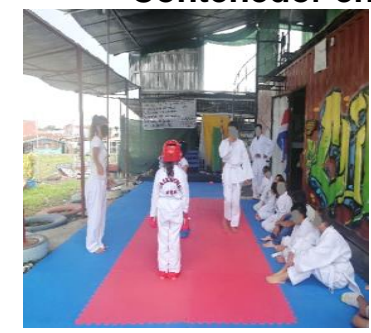

"Clases de Karate en contenedor que es el salón de cultura. Es importante hacer deporte. Ayuda a sacar a los jóvenes de la delincuencia. La Casa de la Cultura de Los Cuadros organiza esta actividad"

Fuente: Magdalena, participante en la investigación de Los Cuadros (2018)

4.2.4 Factor 4: Involucramiento de la niñez y de la juventud para cuidar la comunidad

Únicamente en las comunidades de Dos Cercas y de Alajuelita hubo fotos en las que se mencionaba el involucramiento de la niñez y de la juventud en el cuido y en el embellecimiento de zonas verdes e infraestructura existente (pintar un mural en una pared y las mesas de un parque infantil, sembrar plantas en una zona verde y brindar mantenimiento al playground).

Una persona que participa en la decoración o reparación de una edificación en el barrio, y ha invertido tiempo y esfuerzo en tal actividad, tenderá a cuidar la infraestructura y a evitar que gente inescrupulosa la dañe. La participación de menores de edad en el cuido de 
la comunidad es relevante para crear un sentimiento de pertenencia que pueda perdurar durante la vida. El voluntariado ha logrado este efecto en jóvenes de diversos países (Krauskopf, 2010). Lente en Fuga, una participante de San Felipe de Alajuelita, comentó la Figura 6.

Figura 6

Jóvenes dan mantenimiento a infraestructura comunal en San Felipe de Alajuelita

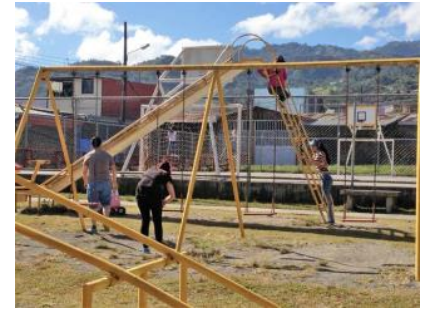

"El Comité de la Niñez y [de la] Adolescencia colaborando en el mantenimiento de las áreas recreativas de la comunidad, y dando el ejemplo de que se pueden cuidar entre todos"

Fuente: Lente en Fuga, participante en la investigación de Alajuelita (2019)

\subsection{Actividades recreativas en las que se participaba en las comunidades}

Al comparar las AR que las fotografías evidenciaron, se halló que, en toda la investigación, hubo participación en nueve de las diez AR de la clasificación de Salazar Salas (2017). La única AR que no se identificó en las fotos fue la de pasatiempos. Las imágenes también mostraron que cuatro AR (recreación física, recreación artística, recreación social y recreación educativa) se realizaron en las cuatro comunidades, cuatro AR (recreación al aire libre, recreación espiritual, recreación intelectual y voluntariado) se efectuaron en tres localidades y una AR (recreación turística) se realizó en una comunidad.

Esta participación en actividades recreativas refleja que, a pesar de las diversas barreras que dificultaron el recrearse, las personas de las comunidades negociaron; es decir, encontraron una estrategia para realizar la actividad recreativa deseada (Jackson et al., 1993). En Los Cuadros, las personas pudieron participar en ocho AR; en Dos Cercas, en siete; en Tirrases, en seis, y en Alajuelita, en ocho. La Tabla 2 muestra y permite comparar las AR en las que cada comunidad participó. 
Tabla 2

Comparación de las actividades recreativas en las que se participó en cuatro comunidades costarricenses, 2019

\begin{tabular}{lccccc}
\hline $\begin{array}{c}\text { Actividad recreativa } \\
\text { (AR) }\end{array}$ & $\begin{array}{c}\text { Los } \\
\text { Cuadros }\end{array}$ & $\begin{array}{c}\text { Dos } \\
\text { Cercas }\end{array}$ & $\begin{array}{c}\text { Tirrase } \\
\text { S }\end{array}$ & $\begin{array}{c}\text { Alajuelit } \\
\text { a }\end{array}$ & $\begin{array}{c}\text { Total de comunidades } \\
\text { en las que se realizó } \\
\text { esta AR }\end{array}$ \\
\hline Recreación física & $\sqrt{ }$ & $\sqrt{ }$ & $\sqrt{ }$ & $\sqrt{ }$ & 4 \\
Recreación aire libre & $\sqrt{ }$ & $\sqrt{ }$ & $X$ & $\sqrt{ }$ & 3 \\
Recreación artística & $\sqrt{ }$ & $\sqrt{ }$ & $\sqrt{ }$ & $\sqrt{ }$ & 4 \\
Recreación espiritual & $\sqrt{ }$ & $\sqrt{ }$ & $X$ & $\sqrt{ }$ & 3 \\
Recreación social & $\sqrt{ }$ & $\sqrt{ }$ & $\sqrt{ }$ & $\sqrt{ }$ & 4 \\
Recreación educativa & $\sqrt{ }$ & $\sqrt{ }$ & $\sqrt{ }$ & $\sqrt{ }$ & 4 \\
Recreación intelectual & $\sqrt{ }$ & $X$ & $\sqrt{ }$ & $\sqrt{ }$ & 3 \\
Recreación turística & $X$ & $X$ & $\sqrt{ }$ & $X$ & 1 \\
Voluntariado & $\sqrt{ }$ & $\sqrt{ }$ & $X$ & $\sqrt{ }$ & 3 \\
\hline
\end{tabular}

Fuente: Elaboración propia. Simbología: $\sqrt{ }=\mathrm{AR}$ en la que se participó, $X=A R$ en la que no se participó

\subsubsection{Recreación física}

En la investigación, se determinó que la recreación física se realizaba en las cuatro comunidades. Por ejemplo, en Los Cuadros se ofrecía, entre otras actividades, capoeira a 57 menores de edad; en Dos Cercas, se brindaban ejercicios a mujeres y existían grupos de atletismo; en Tirrases, se realizaba danza del vientre, y en Alajuelita, se hacía ejercicio en las máquinas disponibles en el parque de Alajuelita Centro.

\subsubsection{Recreación al aire libre}

La recreación al aire libre se realizó en tres comunidades en diferentes entornos. En Los Cuadros, las fotos evidenciaron a un grupo de personas adultas mayores sentadas en una zona verde; en Dos Cercas, a jóvenes jugando fútbol en la plaza del pueblo, y en San Felipe de Alajuelita, la participación de un grupo de personas en la inauguración de un parque infantil.

\subsubsection{Recreación artística}

La recreación artística se identificó en las cuatro comunidades y con diversos ejemplos de actividades. Por ejemplo, en Los Cuadros se describió el show de talentos realizado por personas adultas mayores; en Dos Cercas, las manualidades realizadas por señoras; en Tirrases, la participación en la banda musical de la entidad La Cometa, y en la comunidad García Monge de San Felipe de Alajuelita, la participación en una obra de teatro. 


\subsubsection{Recreación espiritual}

En tres comunidades se realizaron actividades de recreación espiritual. En Los Cuadros, se detectó la participación de un grupo de personas adultas mayores en una actividad religiosa; en Dos Cercas, la celebración de la Navidad en el parque de la localidad, y en San Felipe de Alajuelita, el rezo de El Niño.

\subsubsection{Recreación social}

En las cuatro comunidades se participó en recreación social. En Los Cuadros y en San Felipe de Alajuelita, se festejó el cumpleaños de una señora adulta mayor, y en Dos Cercas, una fiesta de personas adultas mayores. En Tirrases, Alejandra brindó un ejemplo de este tipo de actividad recreativa (Ver Figura 7).

Figura 7

Recreación Social en Tirrases: té de canastilla

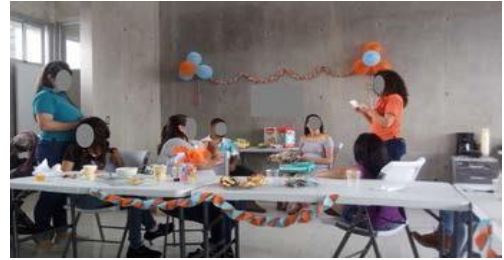

"Amigos de La Cometa celebrando la llegada de un nuevo miembro a la familia de La Cometa."

Fuente: Alejandra, participante en la investigación de Tirrases (2018)

\subsubsection{Recreación educativa}

Diversas actividades de recreación educativa se identificaron en las cuatro comunidades. En Los Cuadros, se brindó una charla a las personas adultas mayores acerca del envejecimiento activo; en Dos Cercas, un curso de manualidades a mujeres; en Tirrases, un curso para aprender a hacer pan francés a señoras, y en Alajuelita, un curso de teatro para menores de edad.

\subsubsection{Recreación intelectual}

La recreación intelectual se identificó en tres comunidades. En Los Cuadros, se realizó un bingo con la población adulta mayor, y en Alajuelita, con personas de diferente edad. En Tirrases, menores de edad aprendieron acerca de robótica.

\subsubsection{Recreación turística}

Solo en la comunidad de Tirrases las fotografías mostraron la recreación turística cuando un grupo de personas amigas asistió al Teatro Nacional a una actividad cultural y luego fue a comer. 


\subsubsection{Voluntariado}

El voluntariado se identificó en tres comunidades. En Los Cuadros, una dama voluntaria le cortó el pelo a una señora de recursos económicos limitados, y en Alajuelita, un grupo de jóvenes brindó mantenimiento a una instalación recreativa para menores de edad. En Dos Cercas, Lucecita comentó el voluntariado realizado (ver Figura 8).

Figura 8

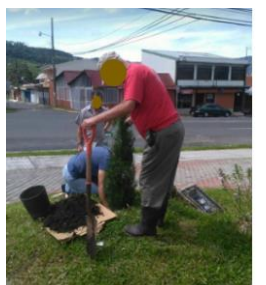

Voluntariado en Dos Cercas: siembra de árbol

Fuente: Lucecita, participante en la investigación de Dos Cercas (2018)

\subsection{Empoderamiento de las participantes}

Otros resultados significativos de este estudio muestran el empoderamiento de las mujeres al sentirse reconocidas por sus opiniones, análisis del contexto social y su entorno. Según diferentes personas autoras, el empoderamiento sugiere metas, objetivos y estrategias para implementar un cambio social mediante el respeto mutuo, la reflexión crítica y la participación grupal como una forma de ejercer influencia sobre las decisiones que afectan el funcionamiento organizacional y la calidad de vida de una comunidad (Erazo Caicedo, Jiménez Ruiz y López Morales, 2014; Rappaport, 1981; Zimmerman, 2000).

El proceso de empoderamiento es específico para cada mujer y es fomentado por la educación no formal de la discriminación entre géneros. Rubin (1975) manifestaba que el sistema sexo-género, un concepto teórico de la década de 1970, indicaba la existencia de una relación desigual de poder entre hombres y mujeres, la cual se fundamentaba en diferencias biológicas y culturales. Las mujeres de este estudio sintieron que podían expresarse, ya fuera en el plano individual o colectivo, al crear vínculos sociales para denunciar los problemas que afectaban las cuatro comunidades (Budig et al., 2018). Según Thompson (1992), el conocimiento se elabora de manera social y los privilegios se inician y perpetúan por medio de las instituciones sociales.

Una de las finalidades de este estudio era lograr, por medio del uso de Fotovoz, la emancipación de las participantes para producir un cambio social y cultural que las beneficiara y que tomaran decisiones individuales o colectivas que previamente no se 
atrevían a tomar. Este cambio se evidenció con el trabajo de las mujeres al unirse para reclamar y denunciar circunstancias de desigualdad de ciertas condiciones en la comunidad que las afectaban a ellas, a sus familias y a quienes vivían en el lugar. El trabajo en grupo promovió este actuar, por el respaldo conjunto que las mujeres experimentaron. Estos resultados coinciden con los de otros estudios porque las participantes adquirieron confianza en sus propias voces y se sintieron valoradas al compartir sus historias (Juniu y Salazar Salas, 2016; Morgan et al., 2010; Salazar Salas y Juniu, 2019a).

Algunas de las participantes de la investigación brindaron su opinión al respecto:

$\checkmark$ Solimar, una participante de Tirrases, mencionó: "Este proyecto de Fotovoz me ha encantado porque uno puede expresarse por medio de ustedes, hacerse escuchar, hacer llegar las inconformidades, pero también el agradecimiento de lo bonito."

$\checkmark$ Alejandra, también de Tirrases, indicó: la voz somos todas las Alejandras de Tirrases que estamos quejándonos de $X$ cosa y somos todas las Alejandras de Tirrases que estamos agradeciendo aquel otro punto. La voz es de todos en general pero no de uno solo. Así, todas las Jecas del barrio van a decir, "mire, yo pensaba eso, y yo no se lo había dicho a nadie; pero qué bueno que lo dijeron ahí". Son todas las Solimares de aquí que dicen, "mire, sí, yo esa parte la había pensado, que tal vez debían cambiarlo, que debían ayudar en esto, en lo otro, pero no sabía a quién decírselo". Es algo bonito porque es la voz de todos y de ninguno en especial.

\section{Conclusiones}

Con base en el objetivo de este artículo, se concluye que las personas en las cuatro comunidades realizaban diversas actividades recreativas. Generalmente, se piensa que quienes viven en localidades en vulnerabilidad social no se recrean; no obstante, las fotos tomadas por las participantes evidenciaron lo opuesto. Las imágenes mostraron que, de los diez tipos de actividades recreativas de la clasificación de Salazar Salas (2017), en Los Cuadros, las personas se recrearon en ocho actividades recreativas; en Dos Cercas, en siete; en Tirrases, en seis, y en Alajuelita, en ocho. La única actividad recreativa que no se identificó en las fotos de las cuatro localidades fue la de pasatiempos. Este hallazgo muestra que, incluso, en situaciones desfavorables, las personas pueden negociar para encontrar la forma de realizar la actividad recreativa de su interés. Este actuar concuerda con la teoría de las barreras (Crawford y Godbey, 1987) y con la teoría de la negociación (Jackson et al., 1993). Además, las barreras que se identificaron en las cuatro comunidades, como las que 
dificultaban la participación recreativa, fueron más numerosas que los factores que fomentaban el recrearse.

Las barreras que obstaculizaron las actividades recreativas en las cuatro comunidades fueron las estructurales, según la clasificación de Crawford y Godbey (1987). Algunas de ellas fueron la falta de instalaciones recreativas o de su mantenimiento, contaminación con basura, diseño urbano ineficiente y falta de ayuda del gobierno con respecto a infraestructura (Anaza y McDowell, 2013; Bioenciclopedia.com, 2015; Koohsari et al., 2015; OMS, 2010, 2017).

La participación en actividades recreativas en las cuatro comunidades fue promovida por "factores protectores", los cuales generan resiliencia en las personas para desenvolverse en situaciones difíciles, como las de esas localidades. Esta condición pudo haber promovido la negociación para encontrar opciones recreativas entre las diversas realidades conflictivas del diario vivir. Algunos factores que facilitaron la participación en recreación fueron el apoyo gubernamental y de la empresa pública, la organización en las comunidades, las instalaciones recreativas que se poseían y los programas recreativos ofertados.

En las cuatro comunidades, las mujeres reflejaron haber dominado la conceptualización de la recreación. Este logro fue producto de la educación no formal recibida del tema, y se comprobó en el empleo de vocabulario recreativo en conversaciones y narrativas. Esta investigación buscó darles a conocer a las comunidades la importancia de la recreación para tener calidad de vida, para mejorar las áreas e instalaciones recreativas y los programas, para aumentar la participación en actividades recreativas y para favorecer que la comunidad general obtuviera los beneficios que brinda la recreación. Esta iniciativa generó, en las mujeres, nuevos conocimientos y aprendizajes, y una conciencia más crítica sobre las condiciones ambientales y sociales de sus comunidades.

El uso de Fotovoz ofreció un nuevo enfoque de investigación para examinar temas relacionados con la recreación, promovió la transformación en la percepción de las mujeres sobre las actividades recreativas y la comunidad. Las participantes abordaron las necesidades de sus comunidades e influyeron en la toma de decisiones locales. Las investigadoras y las mujeres compartieron los hallazgos del proyecto con las autoridades municipalidades para solicitar la implementación de las recomendaciones indicadas en el documento que recibieron. 


\section{Limitaciones}

En esta investigación, la principal dificultad que se tuvo fue la falta de motivación de las mujeres para participar. Al comentar el tema con otros grupos investigadores manifestaron que, en muchas ocasiones, pocas personas en vulnerabilidad social participan en estudios sin solicitar nada a cambio, pero, la mayoría no piensa de esa manera. Esa situación fue quizá la que ocurrió en este caso.

También, en las municipalidades, la celeridad de trámites de las alcaldías y su personal administrativo y su participación en la resolución de las situaciones reportadas no fueron los esperados. Cuando se delegaron tareas, esta forma de trabajo no resultó. En consecuencia, las participantes empezaron a gestionar, ellas mismas, los temas en varias instituciones.

\section{Referencias}

AFP. (16 agosto, 2019). Costa Rica anuncia obras de infraestructura para impulsar economía. El Universal. Recuperado de https://www.eluniversal.com/internacional/48229/costa-rica-anuncia-obras-deinfraestructura-para-impulsar-economia

Anaza, Emeka. y McDowell, Jacqueline. (2013). An investigation of constraints restricting urban Nigerian women from participating in recreational sport activities. Journal of Leisure Research, 45(3). 324-344.

Arenas Ramírez, Aaron. (18 octubre, 2016). ¿Qué es la responsabilidad social corporativa? Recuperado de https://www.gestiopolis.com/la-responsabilidad-social-corporativa/

Benavides, Carolina. (2015, 17 diciembre). Crecimiento de Costa Rica atado por mala infraestructura. Revista Construir. Recuperado de http://revistaconstruir.com/crecimiento-costa-rica-se-ve-atado-mala-infraestructura/

Bioenciclopedia.com. (s.f.). Contaminación por basura. Recuperado de http://www.bioenciclopedia.com/contaminacion-por-basura/

Budig, Kirsten., Diez, Julia., Conde, Paloma., Sastre, Marta., Hernán, Mariano. y Franco, Manuel. (2018). Photovoice and empowerment: Evaluating the transformative potential of a participatory action research project. BioMed Central Public Health, 18(1), 432. https://doi.org/10.1186/s12889-018-5335-7

Calzadilla, Sandra., Price, Rotsen., Riveros, Amaylín. y Mateo, Cristina. (2000). La organización comunitaria. Análisis de un proceso exitoso: Comunidad Las Casitas de La Vega. Revista Venezolana de Análisis de Coyuntura, 6(1), 189-212.

Campos, Jaclin. (6 junio, 2016). Basura y riesgo de enfermedad. Listin Diario. Recuperado de https://listindiario.com/la-vida/2016/06/06/421946/basura-y-riesgo-de-enfermedades 
Club de Excelencia en Sostenibilidad de España. (2017). Estudio multisectorial del estado de la responsabilidad social en Costa Rica. Recuperado de http://www.clubsostenibilidad.org/publicaciones/estudio-multisectorial-sobre-el-estadode-la-responsabilidad-social-en-costa-rica-2017/

Cohen, Deborah. y Crabtree, Benjamin. (2006). Critical theory paradigms. En Robert Wood Johnson Foundation, Qualitative research guidelines project. Recuperado de http://www.qualres.org/HomeCrit-3518.html

Conceptodefinición.de. (2019). Definición de antivalores. Recuperado de https://conceptodefinicion.de/antivalores/

Crawford, Duane. y Godbey, Geoffrey. (1987). Reconceptualizing barriers to family leisure. Leisure Sciences, 9(2), 119-127.

Defensoría de los Habitantes, Universidad de Costa Rica y Centro de Investigación y de Capacitación en Administración Pública. (2018). Informe de resultados 2018. Índice de transparencia del sector público costarricense. Basado en sitios web. Cuarta medición. Recuperado http://kerwa.ucr.ac.cr/bitstream/handle/10669/76522/2018\%20Informe\%20ITSP.pdf?se quence $=1$ \&isAllowed $=y$

Echeverría, Jaime. y Cantillo, Bernal. (2013). Instrumentos económicos para la gestión del agua. Ambientales, 45(1), 13-22. Recuperado de https://dialnet.unirioja.es/servlet/articulo?codigo $=5536182$

Enciclopedia de Ejemplos. (2019). Irrespeto. Recuperado de https://www.ejemplos.co/20ejemplos-de-irrespeto/

Erazo Caicedo, María Isabel., Jiménez Ruiz, María del Carmen. y López Morales, Carmelina. (2014). Empoderamiento y liderazgo femenino; su papel en la autogestión comunitaria en el corregimiento El Hormiguero - Valle del Cauca. Avances en Psicología Latinoamericana, $\quad 32(1), \quad 149-157$. https://dialnet.unirioja.es/servlet/articulo?codigo $=4798418$

Fínez Silva, María José. y García Montero, Alejandro Javier. (2012). Relación entre la resiliencia personal y las estrategias de afrontamiento en estudiantes. International Journal of Developmental and Educational Psychology INFAD Revista de Psicología, 4(1), 111-116. Recuperado de https://www.researchgate.net/publication/323755927 Relacion entre la resiliencia pe rsonal y las estrategias de afrontamiento en estudiantes

Gamboa Gamboa, Miguel Francisco. (2018). El jardín y "el terremoto olvidado": Crónicas del terremoto de Pérez Zeledón (03 de julio de 1983) (2a. ed.). San José, Costa Rica: Universidad de Costa Rica, Vicerrectoría de Acción Social, Iniciativas Estudiantiles de Acción Social. Recuperado de http://kerwa.ucr.ac.cr/handle/10669/15246 
Gómez Díaz de León, Carlos. y de León de la Garza, Elda Ayde. (2015). Capítulo 11. Método comparativo. En Karla Sáenz López y Gerardo Tamez González (Coordinadores), Métodos y técnicas cualitativas y cuantitativas aplicables a la investigación en ciencias sociales (pp. 223-251). México: Tirant Humanidades.

Henderson, Karla. y Hickerson, Benjamin. (2007). Women and leisure: Premises and performances uncovered in an integrative review. Journal of Leisure Research, 39(4), 591-610.

Inseguridad en Costa Rica. (11 noviembre, 2012). Causas de la inseguridad en Costa Rica. Recuperado de https://inseguridadcostarica.blogspot.com/2012/11/causas-de-lainseguridad-en-costa-rica.html

Instituto Nacional de Estadística y Censos, Costa Rica. (2014). Encuesta nacional de hogares julio 2014. Resultados generales. Recuperado de https://www.inec.cr/sites/default/files/documentos/empleo/metodologias/manuales/mee naho2014-02.pdf

Jackson, Edgar., Crawford, Duane. y Godbey, Geoffrey. (1993). Negotiation of leisure constraints. Leisure Sciences, 15(1), 1-11.

Jadue J., Gladys., Galindo M., Ana. y Navarro N., Lorena. (2005). Factores protectores y factores de riesgo para el desarrollo de la resiliencia encontrados en una comunidad educativa en riesgo social. Estudios Pedagógicos (Valdivia), 31(2), 43-55. Recuperado de https://dx.doi.org/10.4067/S0718-07052005000200003

Jiménez, Sergio. (26 julio, 2016). Video: Vecinos construyen aceras malas por presión municipal en Coronado. La Prensa Libre. Recuperado de http://www.laprensalibre.cr/Noticias/detalle/78435/video:-vecinos-construyen-acerasmalas-por-presion-municipal-en-coronado

Juan, David. (2020). Reflexiones sobre la pobreza. Recuperado de http://ayudapobreza.solidariaonline.org/reflexiones-sobre-la-pobreza/

Juniu, Susana. y Salazar Salas, Carmen Grace. (2016). La Capri [Power Point]. Reporte de la investigación con técnica de Fotovoz durante el primer semestre de 2016. San José, Costa Rica: Autoras.

Kjelstad, Bjorn. (16 agosto, 2018). ¿Cuál es la causa de la creciente violencia en Costa Rica? InSight Crime, Análisis. Recuperado de https://es.insightcrime.org/noticias/analisis/causa-creciente-violencia-costa-rica/

Koohsari, Javad., Mavoa, Suzanne., Villanueva, Karen., Sugiyama, Takemi., Badland, Hannah., Kaczynski, Andrew., Owen, Neville. y Giles-Corti, Billie. (2015). Public open space, physical activity, urban design and public health: Concepts, methods and research agenda. Health \& Place, 33, 75-82. doi: http://dx.doi.org/10.1016/..healthplace.2015.02.009 
Krauskopf, Dina. (2010). Perspectivas para el desarrollo del voluntariado juvenil. Revista Observatorio de Juventud, (26), 13-23. Recuperado de https://issuu.com/informacionkoru/docs/revistaobservatorio26

Lara, Juan Fernando. (31 diciembre, 2016). Enorme desperdicio de agua pone a correr al AyA. La Nación. Recuperado de https://www.nacion.com/elpais/infraestructura/enorme-desperdicio-de-agua-pone-a-correr-alaya/Q32YGWX3TVGI3FR6EHR5GAZG3E/story/

López Noguero, Fernando. (2002). El análisis de contenido como método de investigación. XXI Revista de Educación, (4), 167-179. Recuperado de http://rabida.uhu.es/dspace/bitstream/handle/10272/1912/b15150434.pdf?sequence=1

Loría Ramírez, Max. (2015). Evolución de la seguridad ciudadana en el 2014. En Vigésimo primer Informe Estado de la Nación en Desarrollo Humano Sostenible 2014. San José, Costa Rica: Estado de la Nación. Recuperado de https://studylib.es/doc/7275923/evoluci\%C3\%B3n-de-la-seguridad-ciudadana-2014

Marín, Adrián. (14 mayo, 2019). Aguas estancadas en un caño causan molestias a vecinos de Cartago. Telenoticias. Recuperado de https://www.teletica.com/225654 aguasestancadas-en-un-cano-causan-molestias-a-vecinos-de-cartago

Meléndez, Kenneth. (2016, 29 junio). Juegos nacionales se realizarán solo en cantones con infraestructura deportiva. La Nación. Recuperado de https://www.nacion.com/purodeporte/otros-deportes/juegos-nacionales-se-realizaran-solo-en-cantones-coninfraestructura-deportiva/TU45M6VBSBBR5IXJLAYBXH6G3I/story/

Ministerio de Obras Públicas y Transportes, Costa Rica. (2018). Ciudadanos recuperaron aceras y uso de cocheras tras sanciones por mal estacionamiento. Recuperado de https://www.elmundo.cr/costa-rica/ciudadanos-recuperaron-aceras-y-uso-de-cocherastras-sanciones-por-mal-estacionamiento/

Ministerio de Planificación Nacional y Política Económica, Costa Rica. (2014). Plan nacional de desarrollo 2015-2018 "Alberto Cañas Escalante". San José, C.R.: el Autor. Recuperado de http://extwprlegs1.fao.org/docs/pdf/cos145028.pdf

Morgan, Marie., Vardell, Rosemarie., Kintner-Duffy, Victoria., Lower, Joanna., Ibarra, Laura. y Cecil-Dyrkacz, Joy. (2010). Empowering women through Photovoice: Women of La Carpio, Costa Rica. Journal of Ethnographic \& Qualitative Research, 5(1), 31-44.

Municipalidad de Curridabat, Costa Rica. (2020). Centros de desarrollo humano. Recuperado de http://www.curridabat.go.cr/inicio/servicios/

Murillo Arce, Rodrigo. (14 julio, 2016). "Son muchos los años de rezago en infraestructura deportiva". Diario Extra. Recuperado de http://www.diarioextra.com/Noticia/detalle/299638/son-muchos-anos-de-rezago--eninfraestructura-deportiva 
Observatorio de Responsabilidad Social Corporativa. (2019). Qué es RSC. Recuperado de https://observatoriorsc.org/la-rsc-que-es/

Organización Mundial de la Salud [OMS]. (2010). Recomendaciones mundiales sobre actividad física para la salud. Recuperado de https://apps.who.int/iris/bitstream/handle/10665/44441/9789243599977 spa.pdf

Organización Mundial de la Salud [OMS]. (6 diciembre, 2011). Definición. Recuperado de https://organizacionmundialdelasaludoms.blogspot.com/2011/12/definicion.html

Organización Mundial de la Salud [OMS]. (16 mayo, 2013). Proyecto de plan de acción integral sobre salud mental 2013-2020. Informe de la Secretaría. Recuperado de http://apps.who.int/gb/ebwha/pdf files/WHA66/A66 10Rev1-sp.pdf

Organización Mundial de la Salud [OMS]. (12 julio, 2017). 2100 millones de personas carecen de agua potable en el hogar y más del doble no disponen de saneamiento seguro. Recuperado de http://www.who.int/es/news-room/detail/12-07-2017-2-1-billionpeople-lack-safe-drinking-water-at-home-more-than-twice-as-many-lack-safe-sanitation

Organización Mundial de la Salud [OMS]. (23 febrero, 2018). Actividad física. Recuperado de https://www.who.int/es/news-room/fact-sheets/detail/physical-activity

Organización Panamericana de la Salud. (2010). Saneamiento rural y salud. Capítulo 1: Ambiente $y$ salud. Recuperado de https://www.paho.org/hq/dmdocuments/2010/Sanemiento-Capitulo1.pdf

Parry, Diana., Johnson, Corey. y Steward, William. (2013). Leisure research for social justice: A response to Henderson. Leisure Sciences, 35(1), 81-87. doi: 10.1080/01490400.2013.739906

Pérez Del Pozo, Paloma. (2019). Cómo la basura perjudica nuestra salud y al medio ambiente. Recuperado de https://www.alimentatubienestar.es/la-basura-perjudicanuestra-salud-y-medio-ambiente/\#Contaminacion ambiental

Periódico El Gaucho. (13 diciembre, 2015). Las tristes causas de la delincuencia. Recuperado de https://periodicoelguacho.wordpress.com/2015/12/13/las-tristescausas-de-la-delincuencia/

Presidencia de la República de Costa Rica. (2 mayo, 2019). Estado político de la República y los asuntos de la administración-Informe de labores 2019. Recuperado de https://presidencia.go.cr/comunicados/2019/05/estado-politico-de-la-republica-y-losasuntos-de-la-administracion-informe-de-labores-2019/

Programa Estado de la Nación, Costa Rica. (2016). Informe Estado de la Nación en desarrollo sostenible humano. Capítulo 2 Equidad e integración social. San José, Costa Rica: Autor. Recuperado de http://repositorio.conare.ac.cr/handle/20.500.12337/70 
Programa Estado de la Nación, Costa Rica. (2019). Informe Estado de la Nación en desarrollo sostenible humano 2018. Resumen. San José, Costa Rica: Servicios Gráficos AC. Recuperado de http://repositorio.conare.ac.cr/handle/20.500.12337/7808

Quirós Rossi y Asociados. (11 marzo, 2014). Arquitectura recreativa y deportiva en Costa Rica. Recuperado de http://quirosrossi.com/blog/arquitectura-recreativa-deportivacosta-rical

Rappaport, Julian. (1981). In praise of paradox: A social policy of empowerment over prevention. American Journal of Community Psychology, 9, 1-25.

Riddick, Carol Cutler. y Russell, Ruth Virginia. (2015). Research methods. How to conduct research in recreation, parks, sport, and tourism (3a. ed.). Urbana, IL: Sagamore Publishing.

Rodríguez Pimentel, Héctor. (2017). Las aguas residuales y sus efectos contaminantes. Recuperado de https://www.iagua.es/blogs/hector-rodriguez-pimentel/aguasresiduales-y-efectos-contaminantes

Romero Barquero, Cecilia Enith. (2015). La recreación en el fomento de la resiliencia. Revista de Ciencias de la Actividad Física UCM, 16(1), 63-80.

Rubin, Gayle. (1975). The traffic in women: Notes on the political economy of sex. En Rayna Reiter (Ed.). Toward and anthropology of women (pp. 157-210). New York: Monthly Review Press.

Salazar Salas, Carmen Grace. (2017). Recreación (2da. ed.). San José, Costa Rica: Editorial Universidad de Costa Rica.

Salazar Salas, Carmen Grace. y Juniu, Susana. (2017). Vivencias de mujeres de Los Cuadros acerca de su recreación mediante el uso de Fotovoz. [Power Point]. Reporte de la investigación. San José, Costa Rica: Autoras.

Salazar Salas, Carmen Grace. y Juniu, Susana. (2018a). Vivencias de mujeres de Dos Cercas acerca de su recreación mediante el uso de Fotovoz. [Power Point]. Reporte de la investigación. San José, Costa Rica: Autoras.

Salazar Salas, Carmen Grace. y Juniu, Susana. (2018b). Vivencias de mujeres de Tirrases acerca de su recreación mediante el uso de Fotovoz. [Power Point]. Reporte de la investigación. San José, Costa Rica: Autoras.

Salazar Salas, Carmen Grace. y Juniu, Susana. (2019a). Documentación de vivencias recreativas de un grupo de mujeres de Los Cuadros mediante Fotovoz. Revista Actualidades Investigativas en Educación, 19(2), 1-32. DOI 10.15517/aie.v19i2.36901

Salazar Salas, Carmen Grace. y Juniu, Susana. (2019b). Vivencias de mujeres de Alajuelita acerca de su recreación mediante el uso de Fotovoz. [Power Point]. Reporte de la investigación. San José, Costa Rica: Autoras. 
Soriano Ayala, Encarnación. y Cala, Verónica. (2016). Fotovoz: Un método de investigación en ciencias sociales y de la salud. Madrid: La Muralla

Sostenibilidad para todos. (2018). Desperdicio de agua en las ciudades. Recuperado de https://www.sostenibilidad.com/agua/desperdicio-de-agua-en-las-ciudades/

Tendencias en Arquitectura Deportiva y Recreativa. (9 marzo, 2016). Área Urbana. Revista de Actualidad, Tecnología y Equipamiento para Municipios y Prestadores de Servicios Públicos. Recuperado de https://areaurbana.com/tendencias-en-arquitecturarecreativa-y-deportiva/

Thompson, Linda. (1992). Feminist methodology for family studies. Journal of Marriage and the Family, 54(1), 3-18. DOI 10.2307/353271

Torres Samamé, Melissa Elizabeth. (2015). Red de parques y renovación del ex parque zonal: Propuesta para la revaloración del espacio público, áreas verdes e infraestructura recreativa en el núcleo urbano de Chiclayo (Tesis de licenciatura en Arquitectura). Universidad Católica Santo Toribio de Mogrovejo, Chiclayo, Perú. Recuperado de https://core.ac.uk/download/pdf/71999949.pdf

Universidad Internacional de Valencia. (17 mayo, 2015). ¿Qué se entiende por educación no formal? Recuperado de https://www.universidadviu.es/que-se-entiende-por-educacionno-formal/

Ventas, Leire. (29 octubre, 2015). Por qué Costa Rica está dejando de ser la "Suiza de Centroamérica". BBC News. Mundo. Recuperado de https://www.bbc.com/mundo/noticias/2015/10/151027 costa rica violencia narcotrafic o homicidios suiza centroamerica paraiso seguridad IV

Wang, Caroline., Burris, Mary Ann. y Ping, Xiang Yue. (1996). Chinese village women as visual anthropologists: A participatory approach to reaching policymakers. Social Science and Medicine, 42(10), 1391-1400.

Wang, Caroline. y Burris, Mary Ann. (1994). Empowerment through photo novella: Portraits of participation. Health Education Quarterly, 21(2), 171-186.

Wang, Caroline. y Burris, Mary Ann. (1997). Photovoice: Concept, methodology, and use for participatory needs assessment. Health Education and Behavior, 24(3), 369-387.

Yoder, Daniel. y Tortosa Martínez, Juan. (2013). Leisure and recreation for individuals in society. En Human Kinetics (Ed.), Introduction to recreation and leisure (2da. ed.; pp. 61-76). Champaign, IL: Human Kinetics.

Zimmerman, Mark A. (2000). Empowerment theory. Psychological, organizational and community levels of analysis. En Julian Rappaport y Edward Seidman (Eds.), Handbook of Community Psychology (pp. 43-63). New York: Kluwer Academic/Plen. 
Revista indizada en
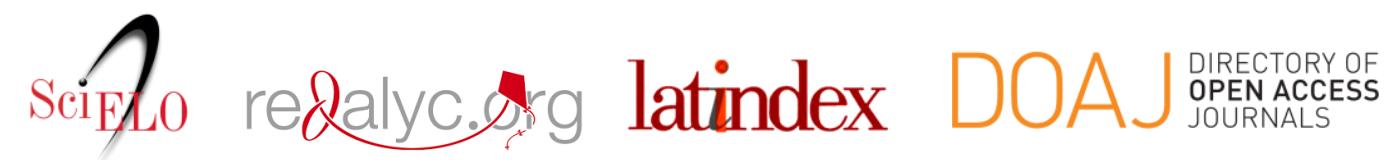

Distribuida en las bases de datos:

- Dialnet

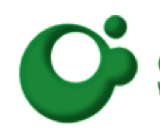
SHERPA/RøMEO

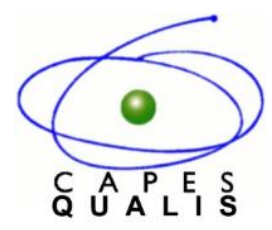

MIAR 